Check for updates

Ethox Centre, Nuffield Department of Population Health, University of Oxford

2 Population, Policy and Practice Research and Teaching Department, UCL Great Ormond Street Institute of Child Health, London

3 Population Health Research Institute, St George's University of London

4 Institute for Social Marketing and Health, University of Stirling

Correspondence to: M Parker michael.parker@ethox.ox.ac.uk, H Bedford h.bedford@ucl.ac.uk

Cite this as: BMJ 2021;374:n1903 http://dx.doi.org/10.1136/bmj.n1903 Published: 4 August 2021

COVID-19

\title{
Should covid vaccination be mandatory for health and care staff?
}

New English law will make vaccination a condition of employment for eligible care home workers, following similar moves in Italy, France, and Greece for healthcare staff. This is reasonable, argues Michael Parker, because care institutions have a duty to protect patients; but Helen Bedford, Michael Ussher, and Martine Stead worry that such a blunt approach is unnecessary and could be counterproductive

\author{
Michael Parker, ${ }^{1}$ Helen Bedford, ${ }^{2}$ Michael Ussher, ${ }^{3,4}$ Martine Stead ${ }^{4}$
}

\section{Yes-Michael Parker}

Patient safety is ultimately the responsibility of health and social care institutions. With regard to employment practice, these institutions have a duty to employ only workers whose presence would not place patients at unnecessary risk. Frontline care roles should not be offered to people unwilling to be vaccinated against high risk infections. This applies not only to direct employment but also to contract and agency staff.

The situation is less clear where existing staff are concerned, as employers have responsibilities not only for their patients but also to their staff. These include obligations of non-discrimination and ensuring reasonable working conditions.

But healthcare staff, too, have responsibilities. They should, for example, be willing to modify their practice in the interest of patient safety. If hospital chefs refuse to comply with new safe food preparation guidance, they have no good reason to expect to continue to be employed. So too in frontline healthcare roles, staff are rightly required to modify their practice in the light of evidence about patient safety.

\section{Low risk from vaccination}

Where might vaccination against a new infectious disease fit into this? In terms of personal morality, the low risk from vaccination means that health workers whose unvaccinated status poses a risk to patients have an obligation to accept vaccination. They have what is sometimes referred to as a "duty of easy rescue.” Although covid-19 vaccines confer less than $100 \%$ protection and are available under emergency approvals, the evidence of impact on patient safety and of low risk of adverse effects is sufficient to establish this duty, other than in exceptional cases such as where the risk of serious health implications that vaccination poses to an individual staff member is high.

But should health and care workers be compelled to accept vaccination? There are many things staff should arguably do on moral grounds that it would be wrong for employers to require as a condition of continued employment, such as being welcoming and friendly to all patients. Legitimate compulsion, then, requires further justification: what are employers' responsibilities in relation to existing unvaccinated staff and the safety of patients?

Employers should certainly actively promote vaccination, establish a culture in which vaccination is expected, and make it as easy as possible for employees to be vaccinated. They should also move staff who are reluctant to be vaccinated, or those with a medical contraindication, to roles where the risk to patients is low. Ideally, this should be done immediately for all unvaccinated staff. There may, however, be some situations in which an immediate reallocation would create greater risk than the continued presence of the unvaccinated care worker.

Transitions of this kind require careful, responsible management and can take time. In such situations a formal risk assessment should be undertaken and a plan put in place for the safe and timely reallocation of staff. The fact that there will be times when moving staff would put patients at greater risk-where, for example, recruitment is difficult-is not a justification for doing nothing.

\section{Obligations to patients}

What should happen when all reasonable alternatives have been explored but it is still not possible to swiftly ensure that patients are cared for by vaccinated staff? At this point, for employers to meet their obligations to patients they should make it mandatory for all remaining frontline staff without a serious medical contraindication to be vaccinated. A plan should be put in place to move those in whom it is contraindicated to other roles as quickly as possible. Any such plan should consider whether an individual staff member might leave if required to be vaccinated and assess whether this would put specific patients at serious risk of harm. Where there is clear evidence that this is the case a temporary, time limited delay-perhaps of up to two months-accompanied by a structured plan of action may be appropriate.

Although health and social care institutions are ultimately responsible for the safety of patients, it is worth repeating that the low levels of risk involved mean there is a strong argument for considering the vast majority of health and social care staff to have a personal moral obligation to accept vaccination against infectious diseases that put their patients at significant risk of serious harm. 


\section{No-Helen Bedford, Michael Ussher, and Martine Stead}

Health and social care workers have a duty of care to be vaccinated against covid-19 to protect their patients and care home residents, as well as protecting themselves, their families, and the wider community. On 14 July 2021, the House of Commons approved the requirement for staff without a medical contraindication working in Care Quality Commission regulated care homes in England to have two doses of covid vaccine. Italy, France, and Greece have recently made vaccination mandatory for healthcare workers. ${ }^{12}$

\section{Freedom of choice}

We consider that mandatory vaccination is "a blunt instrument to tackle a complex issue" 3 : it is not necessary, acceptable, or the most effective way to achieve high uptake, and it raises serious ethical issues about freedom of choice. Although it can be argued that freedom of choice does not trump protecting patients and care home residents, mandatory vaccination could be counterproductive.

In England, covid vaccine uptake among adults in the general population, and among staff in NHS and older adult care homes, is generally high: $87 \%, 90 \%$, and $87 \%$ of these respective groups have been vaccinated with at least one dose, ${ }^{4}$ although the accuracy of the data on care home workers has been questioned. ${ }^{5}$ However, uptake varies geographically and between sociodemographic groups, with lower uptake or intended uptake (hesitancy) among some minority ethnic groups also reported. ${ }^{6-8}$

Of concern, a large study of healthcare workers reported that those in patient facing roles, including nurses, nursing associates, and midwives, were more likely to be hesitant. ${ }^{7}$ Health and social care workers are obviously not immune to vaccine concerns or susceptibility to misinformation. As with the general population, ${ }^{6}$ exploring the reasons for vaccine hesitancy among these workers is fundamental to informing interventions to improve uptake. ${ }^{7}$

\section{Initiatives to improve vaccine uptake}

Hospital trusts have reported successful initiatives to improve staff vaccine uptake, which address the main reasons for hesitancy..$^{-11}$ These include improving access and providing support for booking vaccine appointments; providing evidence based information in various formats and languages, including regular question and answer sessions in online webinars; and drop-in sessions where concerns are acknowledged and dealt with non-judgmentally.

An "active listening" approach to providing information, while recommending vaccination, builds trust-a key factor in vaccine acceptance. ${ }^{12}$ Importantly, vaccine advocates and ambassadors involved in these initiatives were mainly from minority ethnic groups. Staff reported that vaccine confidence among more senior colleagues, particularly clinicians, was influential. ${ }^{7}$ Since healthcare workers, together with the NHS, are the public's most trusted source of information about covid vaccine, ${ }^{6}$ such strategies may also help to improve vaccine confidence among the wider population.

In the context of concerns about suboptimal vaccine uptake, mandatory vaccination can seem a straightforward solution, requiring less resource than other interventions, but it has downsides. Notably, it may risk increasing resistance to vaccination by damaging trust in the government and other organisations. ${ }^{8}$ This is of particular concern among ethnic minorities, who are over-represented among health and social care workers, have been disproportionately affected by covid-19, are less likely to trust government sources of information, and are more likely to be vaccine hesitant. ${ }^{6}$
In a recent public consultation, $47 \%$ of care home workers did not support mandatory vaccination. ${ }^{13}$ There are reports of staff threatening to leave rather than be forced to be vaccinated, which is a particular concern owing to shortages in NHS and care home staff. ${ }^{14}$ Although this does not seem to have been borne out in Australia, where flu vaccine is mandatory for some health and social care staff, ${ }^{15}$ enforcing vaccination risks damaging the morale of an already pressured essential workforce.

To maximise uptake, mandatory vaccination should be the last resort when other measures have failed. But vaccine uptake is generally already high in health and care workers, and it can be improved with less extreme measures. The UK already has highly successful vaccine programmes across the life course without recourse to compulsion; introducing such a coercive practice now, even if only for specific groups, represents a slippery slope that is best left untrodden.

Competing interests (MP): I have read and understood BMJ policy on declaration of interests and have no relevant interests to declare.

Competing interests (HB/MS/MU): We have read and understood BMJ policy on declaration of interests and declare the following interests: HB is a member of the NICE guideline committee: Vaccine Uptake in the General Population. MS and MU have no competing interests to declare.

Provenance and peer review: Commissioned; not externally peer reviewed.

Wise J. Covid-19: France and Greece make vaccination mandatory for healthcare workers. BMJ 2021;374:n1797. doi: 10.1136/bmj.n1797 pmid: 34261643

Paterlini M. Covid-19: Italy makes vaccination mandatory for healthcare workers. BMJ 2021;373:n905. doi: 10.1136/bmj.n905 pmid: 33824155

BMA. Mandatory vaccination for NHS staff is incredibly complex issue, says BMA. 2021. https://www.bma.org.uk/bma-media-centre/mandatory-vaccination-for-nhs-staff-is-incrediblycomplex-issue-says-bma

NHS England. Covid-19 vaccinations. 2021. https://www.england.nhs.uk/statistics/statisticalwork-areas/covid-19-vaccinations/

Hayes L, Pollock AM. Mandatory covid-19 vaccination for care home workers. BMJ 2021;374:n1684. doi: 10.1136/bmj.n1684 pmid: 34233895

6 Stead M, Jessop C, Angus K, etal. A national survey of attitudes towards and intentions to vaccinate against covid-19: implications for communications.medRxiv 2021 [Pre-print]. https://www.medrxiv.org/content/10.1101/2021.06.29.21259717v1

7 Woolf K, McManus IC, Martin CA, etal. Ethnic differences in SARS-CoV-2 vaccine hesitancy in United Kingdom healthcare workers: results from the UK-REACH prospective nationwide cohort study. Lancet Reg Health Eur 2021. doi: 10.1016/j.lanepe.2021.100180

8 Bell S, Clarke RM, Ismail SA, etal. Covid-19 vaccination beliefs, attitudes, and behaviours among health and social care workers in the UK: a mixed-methods study.medRxiv 2021 [Pre-print]. https://www.medrxiv.org/content/10.1101/2021.04.23.21255971v1

9 Papineni P, Filson S, Martin I, et al. Trusted messengers are key to encouraging vaccine uptake. BMJ Opinion 2021 Jul 24. https://blogs.bmj.com/bmi/2021/06/24/trusted-messengers-are-keyto-encouraging-vaccine-uptake/

10 Azamgarhi T, Hodgkinson M, Shah A, etal. BNT162b2 vaccine uptake and effectiveness in UK healthcare workers-a single centre cohort study. Nat Commun 2021;12:3698. doi: 10.1038/s41467-021-23927-x pmid: 34140469

11 Stead M, Critchlow N, Patel R, MacKintosh AM, Sullivan F. Improving uptake of seasonal influenza vaccination by healthcare workers: Implementation differences between higher and lower uptake NHS trusts in England. Infect Dis Health 2019:24:3-12. doi: 10.1016/j.idh.2018.09.082. pmid: 30541694

12 Lewandowsky S, Cook J, Schmid P, et al. The covid-19 vaccine communication handbook: a practical guide for improving vaccine communication and fighting misinformation. 2021. https://rritools.eu/-/the-covid-19-vaccine-communication-handbook-a-practical-guide-for-improving-vaccinecommunication-and-fighting-misinformation

13 Learner S. Care home calls for covid vaccine to only be mandatory for new employees, after staff threaten to leave. Carehome.co.uk. 23 Jul 2021. https://www.carehome.co.uk/news/article.cfm/id/1653742/care-home-staff-leave-covid-vaccine

14 Department of Health and Social Care. Consultation outcome-Making vaccination a condition of deployment in care homes: government response. Updated 19 Jul 2021. https:/www.gov.uk/government/consultations/making-vaccination-a-condition-of-deploymentin-older-adult-care-homes/outcome/making-vaccination-a-condition-of-deployment-in-carehomes-government-response

15 Seale $\mathrm{H}$. Evidence supports mandatory covid vaccination for aged-care workers. But we need to make it easier too. Conversation 2021. https://theconversation.com/evidence-supports-mandatory-covid-vaccination-for-aged-care-workers-but-we-need-to-make-it-easier-too-163569 
This article is made freely available for use in accordance with BMI's website terms and conditions for the duration of the covid-19 pandemic or until otherwise determined by BMJ. You may use, download and print the article for any lawful, non-commercial purpose (including text and data mining) provided

that all copyright notices and trade marks are retained. 